\title{
ATIVIDADE DA GLUTAMINA SINTETASE (GS) E PROTEÍNA TOTAL EM PLANTAS DE SOJA (Glycine max (L) MERR.) CULTIVADAS EM DIFERENTES NIIVEIS DE ALUMÍNIO E NITROGÊNIO
}

\author{
Liliana Pace ${ }^{1}$ \\ Lilian Ellen Pino-Nunes ${ }^{2}$ \\ Flavio Trevisan ${ }^{2}$ \\ Enio Tiago de Oliveira ${ }^{3}$ \\ Luiz Antonio Gallo ${ }^{4 *}$
}

\section{RESUMO}

Neste experimento foram avaliadas proteína total e a atividade da Glutamina Sintetase (GS) em plantas de soja (Glycine $\max$ L. cv.Br48) cultivadas em casa de vegetação sob diferentes condições nutricionais. A atividade da GS foi determinada através do método adaptado de Elliot (1953). Plantas de soja foram cultivadas em vasos contendo areia lavada e esterilizadas, e foram irrigadas com soluções de Hoagland \& Arnon (1950), modificada com diferentes concentrações de nitrogênio e de alumínio. $\mathrm{O}$ experimento constou de três tratamentos a saber: tratamento com solução de Hoagland normal, tratamento com metade da dose original de nitrogênio e tratamento com solução nutritiva de Hoagland normal mais $100 \mathrm{ppm}$ de alumínio. Foram realizadas coletas periódicas aos 15 , 30,45 e 60 dias após o plantio. O teor de proteína solúvel total decresceu ao longo do tempo em todos os tratamentos, sendo observado um decréscimo maior no tratamento que recebeu alumínio. A atividade da

1 Farmacêutica, Curso Fisiologia e Bioquímica de Plantas- ESALQ/USP

2 Curso de Pós-graduação em Fisiologia e Bioquímica de Plantas - ESALQ/USP

3 Biologo, Lab. Biotecnologia Agricola. Depto. Ciências Biológicas - ESALQ/USP

4 Prof. Dr. do Depto. Ciências Biológicas - Esalq/USP, C.P. 9 CEP: 13418-900 Piracicaba, SP.

*Autor correspondente (luagallo@gesalq.usp.br) 
glutamina sintetase aumentou ate $045^{\circ}$ dia após o plantio, em todos os tratamentos. Após este período houve um decréscimo na atividade nos tratamentos 2 e 3 , indicando um efeito inibidor do íon e da deficiência do nitrogênio na atividade d̦a enzima, no período final de crescimento da planta.

Palavras-chave: Glutamina sintetase, Glycine $\max (\mathrm{L})$ Merrill, alumínio, estresse.

\section{ABSTRACT}

\section{GLUTAMINE SYNTHETASE ACTIVITY (GS) AND PROTEIN IN SOYA BEANS PLANTS (Glycine $\max (L) M E R R$.) GROWING UNDER DIFFERENT NITROGEN AND ALUMINUM CONDITIONS}

In this experiment, total protein and glutamine sintetase activity (GS) in soya beans plants (Glicine max (L) Merrill. cv Br48 growing under different nitrogen and aluminum conditions were evaluated. The GS activity was estimated by Elliot (1953) method. Soya bean plants were grown on Hoagland and Arnon (1950) modified solution containing total nitrogen of $\mathrm{H} \& \mathrm{~A}$, half nitrogen of $\mathrm{H} \& \mathrm{~A}$, and total nitrogen of $\mathrm{H} \& \mathrm{~A}$ plus $100 \mathrm{ppm}$ of aluminum.

The analyses were performed at 15,30, 45 and 60 days after planting. The total soluble protein decreased during the experiment in all the treatments. The decrease in the aluminum treatment was more pronounced. The activity of glutamine sintetase increased till the $45^{\circ}$ day after planting, in all the treatments. Afterwards, there was decreasing activity on treatments two and three, showing the inhibitor effect of aluminum and nitrogen deficiency on the enzyme activity.

Key words: Glutamine Synthetase, Glycine max L., aluminum, stress.

\section{INTRODUÇÃO}

A soja, Glycine max (L). Merrill, é considerada a mais importante oleaginosa cultivada no mundo, devido seu alto valor nutricional, 
proporcionando múltiplas utilizações. Apesar de ser uma espécie cultivada há pouco tempo no Brasil, a cultura ocupa uma posição de destaque na economia agrícola do país, conferindo ao Brasil, desde 1976, a posição de segundo maior produtor mundial. A produção da safra de 1998/1999 foi de aproximadamente trinta e um milhões de toneladas de grãos, com uma produtividade média de $2.400 \mathrm{~kg} / \mathrm{ha}$ (CONAB, 2000).

As primeiras estatísticas revelando a utilização de soja para produção de grãos no Brasil datam de 1941, no Estado do Rio Grande do Sul, que produziu, em 640 ha de área cultivada, 450 toneladas, com um rendimento médio de $700 \mathrm{~kg} / \mathrm{ha}$ (Vernetti, 1983). No Estado do Paraná, a soja foi introduzida por agricultores gaúchos que emigraram para o sudoeste e então para o oeste do Estado. A produção no Paraná cresceu rapidamente até atingir 60.000 toneladas na década de 60 (Kastler et al., 1981). A partir da década de 70 , a cultura da soja evoluiu significativamente nos estados produtores, não só no Sul, mas também nos estados do Centro-Oeste do Brasil. Com o desenvolvimento de novos cultivares adaptados às diferentes regiões agroclimáticas do País, o Brasil tornou-se o maior produtor mundial de soja. A tecnologia de produção e a produtividade da cultura da soja no Brasil têm progredido de forma estável e significativa. Na safra agrícola de 1997/98, o Brasil plantou cerca de 13 milhões de ha com uma produtividade média de $2.300 \mathrm{~kg} / \mathrm{ha}$. O rendimento tem aumentado significativamente nos últimos anos, não apenas em função dos ganhos obtidos pelo melhoramento genético, mas também pela utilização de tecnologias nas áreas de práticas de manejo da cultura e pela utilização de equipamentos mais apropriados às condições brasileiras. Em 2003, o Brasil produziu 52 milhões de toneladas com uma produtividade de $2800 \mathrm{~kg} / \mathrm{ha}$. O germoplasma de soja possui grande diversidade quanto ao ciclo (número de dias da emergência à maturação), variando de 70 dias (para as mais precoces) a 200 dias (para as mais tardias). De modo geral, as variedades brasileiras têm ciclo entre 100 e 160 dias e, para determinada região, podem ser classificadas em grupos de maturação precoce, semiprecoce, média, semitardia e tardia. O ciclo total da planta pode ser dividido em duas fases: vegetativo e reprodutivo. O período total de florescimento pode durar de três a mais de cinco semanas, dependendo do genótipo e do ambiente (Vernetti, 1983). 
O nitrato constitui uma das principais fontes de nitrogênio para as plantas e quando reduzido irá fazer parte de compostos nitrogenados, que estão comprometidos com o metabolismo proteico sendo de fundamental importância para a manutenção da planta. Após sua redução e conversão em amônia será incorporado em moléculas de aminoácidos, os quais, por sua vez, irão fazer parte do "pool" de compostos nitrogenados que se compartimentalizam nas células do vegetal, desta forma a planta produz proteínas e cria condições de desenvolvimento.

Sendo o nitrato a maior fonte de nitrogênio para as planta, as mesmas empregam significante porção do carbono e energia em sua assimilação e transporte. Nitrato serve tanto como nutriente, como um sinalizador e tem um profundo efeito no metabolismo da planta e em seu crescimento (Crawford, 1995). A assimilação do nitrato inicia com sua absorção pelas células corticais da raiz.. Uma vez no simplato, o nitrato pode ser transportado ao vacúolo onde se acumula em altas concentrações (mais que $20 \mathrm{mM}$ ). A absorção primaria também pode ocorrer nas folhas, sendo que o nitrato é transportado via xilema ate a parte aérea. A absorção inicial do nitrato é um processo regulado e realizado por transporte ativo. O nitrato não é por si próprio incorporado em compostos orgânicos, mas deve ser reduzido a amônia. Primeiramente o nitrato é reduzido a nitrito pela redutase do nitrato e posteriormente a amônia pela redutase do nitrito.

Durante estas etapas, ocorre a transferência de 8 elétrons $(2+6)$, mudando o numero de oxidação do nitrogênio de +5 para -3 . Em seguida a amônia formada é assimilada em compostos orgânicos nitrogenados que tem por função o transporte do nitrogênio para a síntese de novos aminoácidos e proteínas. A amônia também pode ser formada no mitocôndrio pela ação da glicina descarboxilase, um complexo formado por 4 enzimas, que levam á formação de metileno tetra hidro folato, amônia e $\mathrm{CO}_{2}$. Para cada duas moléculas de glicina que entram no mitocôndrio, serão formadas uma molécula de serina, $\mathrm{CO}_{2} \mathrm{e} \mathrm{NH}_{4}^{+}$, enquanto um $\mathrm{NAD}^{+}$ é reduzido.

A enzima serina hidroxi metil transferase liga o metileno tetrahidro folato a outra molécula de glicina, para produzir o esqueleto de três carbonos da serina. Para atenuar o efeito tóxico da amônia, e por ser uma 
fonte importante de $\mathrm{N}$, a mesma deve ser reassimilada pela ação da sintetase de glutamina (GS) e da glutamina alfa ceto glutarato amino transferase (Gogat), que formam glutamina e acido glutâmico respectivamente no interior do cloroplasto. A atividade fotorrespiratória nas plantas $\mathrm{C} 3$, consome cerca de 25 a $30 \%$ do carbono que seria fixado pela fotossintese. Assim, a reciclagem da amônia representa uma importante via metabólica, podendo ser maior que a absorção do nitrato pelas plantas (Leegood, 1993).

A amônia é tóxica para todos os organismos vivos, e se a concentração no interior celular alcança $1,0 \mathrm{mM}$, todas as reações fotossintéticas do cloroplasto cessam. Duas enzimas são encarregadas da assimilação da amônia em compostos orgânicos, a sintetase de glutamina, (GS- EC. 6.3.1.2) e a desidrogenase do glutamato, ou desidrogenase glutâmica (GDH - EC. 1.4.1.2).

A principal fonte de amônia, que freqüentemente não é mencionada em livros textos, é aquela gerada pelo processo da fotorrespiração, onde uma molécula de $\mathrm{CO}_{2}$ é liberado na conversão de duas moléculas de glicina para uma de serina, com equivalente liberação de amônia (Lea, 1987). Esta amônia liberada é então reciclada pelo ciclo da GS-Gogat, a uma velocidade de cerca de 10 vezes maior que a redução do nitrato (Wallsgrove et al., 1982). Estudos fisiológicos revelaram que as plantas podem transportar amônia através de múltiplos transportadores como o AMT1 em Arabdopsis e SAT1 em soja (Crawford et al., 2000). Transportadores de amônia formam uma nova família de genes identificados em todos os organismos. Em tomate três genes foram identificados (Von Wiren et al., 2000; Salvemini et al., 2001; Howitt \& Udvardi, 2000; Carvalho et al. 2000).

As enzimas GS, Gogat, GDH, AspAT (aspartato amino transferase) e AS (asparagina sintetase), estão envolvidas no processo de assimilação primária do nitrogênio (Crawford et al., 2000), a partir do solo, tanto quanto na assimilação secundária, durante o processo fotorrespiratório. A enzima Glutamina Sintetase (GS) (EC 6.3.1.2) utiliza glutamato, ATP e amônia, promovendo a produção de glutamina, $\mathrm{ADP}$ e Pi. Além dessa atividade sintetase, a GS funciona de maneira biossintética produzindo 
$\gamma$-glutamilhidroxamato a partir de glutamato, ATP e hidroxilamina, e funciona também como transferase produzindo $\gamma$-glutamilhidroxamato a partir de hidroxilamina (Farnden \& Robertson, 1980). É possivel determinar-se diferentes isoformas possuindo algumas características particulares com relação a sua localização, estabilidade perante o calor, valores de $\mathrm{pH}$ denominados ótimos e até KM de seus diferentes substratos.

Essa enzima é considerada como a principal rota de assimilação de amônia em plantas (Hirel et al., 1984). Estruturalmente a GS é composta predominantemente de oito subunidades, com peso molecular em torno de $47 \mathrm{Kda}$, resultando em um peso molecular total de aproximadamente $380 \mathrm{Kda}$ (Cullimore et al., 1983).

Um dos mais relevantes problemas causados por ions metálicos no solo, é a toxicidade por alumínio, além da salinidade. Estes fatores podem reduzir os índices de colheita, especialmente em solos ácidos comuns nas regiões tropicais. Ao longo da evolução as plantas adquiriram resistência ao alumínio, obtendo assim, capacidade para desenvolveremse neste ambiente (Foy, 1984; Baligar \& Fageria, 1997). Devido a esta relevância há necessidade de maiores estudos com este metal. A maioria dos solos da Região Sudeste e Centro Oeste são ácidos, apresentando grande concentração de íons hidrogênio e/ou alumínio no solo. Teoricamente, a acidez se caracteriza pelos teores de hidrogênio e alumínio no solo. A acidez dos solos promove o aparecimento de elementos tóxicos para as plantas além de causar a diminuição da disponibilidade de nutrientes para as mesmas. As conseqüências são os prejuízos causados pelo baixo rendimento produtivo das culturas. O alumínio é um dos elementos mais abundantes nos solos brasileiros, estando presente em diferentes formas associadas tanto aos componentes cristalinos como à matéria orgânica dos mesmos (Malavolta, 1980).

Segundo Cambraia (1989) e Furlani (1989), a presença de altos níveis de $\mathrm{Al}^{+3}$ livre nos solos ácidos do Brasil é considerado um dos principais fatores limitantes da agricultura brasileira, apesar disto pouco se conhece a respeito dos mecanismos de toxidez do $\mathrm{Al}^{+3}$. Observou-se que a ação prejudicial do $\mathrm{Al}^{+3}$ na célula tem sido associada com um grande número de efeitos e sintomas na planta, interferindo na divisão celular 
nos meristemas radiculares, diminui a respiração e crescimento radicular, aumenta a rigidez da parede celular, inativa os ácidos nucléicos pela formação de complexos, e interfere com a absorção, transporte e metabolismo de $\mathrm{Ca}, \mathrm{Mg}, \mathrm{P}, \mathrm{N}$ e K (Clarkson, 1965; Foy et al., 1978; Matsumoto \& Morimura; 1980; Bennet et al., 1985; Machado, 1987; Wagatsuma et al, 1987).

O presente trabalho teve como objetivo avaliar a atividade da enzima Glutamina Sintetase e proteína total em plantas de soja cultivadas em casa de vegetação sob diferentes condições de nutrição relativas à quantidade de nitrogênio e de alumínio.

\section{MATERIAIS E MÉTODOS}

O plantio de sementes de soja (Glycine max (L) Merrill cv. Br48) foi feito em vasos com cerca de 2 litros de capacidade cada um, cheios de areia lavada em água corrente e esterilizada em autoclave a $100^{\circ} \mathrm{C}$ por 20 minutos. Em cada um deles foram colocadas 8 sementes. As plântulas germinadas sofreram desbaste, selecionando-se 4 plantas por vaso. Esses vasos foram colocados em casa de vegetação localizada no Laboratório de Biotecnologia Agrícola do Depto. de Ciências Biológicas na ESALQUSP - Piracicaba/SP.

O material foi irrigado 2 vezes ao dia, de manhã e à tarde. Depois da primeira semana após a semeadura, foram aplicados, no período da tarde, ao invés de água, $100 \mathrm{~mL}$ de solução nutritiva de Hoagland (Hoagland \& Arnom, 1950), preparada a partir das soluções estoque, em concentrações especificas correspondentes a três tratamentos, descritos abaixo e conforme Tabela 1.

- T1 Tratamento controle: uso de solução nutritiva de Hoagland completa.

- T2 Tratamento com deficiência: uso de solução nutritiva de Hoagland com nitrogênio reduzido pela metade.

- T3 Tratamento controle para teste com alumínio: uso de solução nutritiva de Hoagland completa, mais dose de alumínio. 
Tabela 1. Composição química das diferentes soluções nutritivas (Hoagland \& Arnom, 1950), adaptadas para suprimento de $\mathrm{K}^{+}$e $\mathrm{Ca}^{++}$nos tratamentos com deficiência de nitrogênio.

\begin{tabular}{|c|c|c|c|c|}
\hline \multicolumn{5}{|c|}{ Tratamentos (mI.L de solução) } \\
\hline & & \multicolumn{3}{|c|}{$\mathrm{pH} 5,7$} \\
\hline Composto & Molar & $\mathrm{T} 1$ & $\mathrm{~T} 2$ & $\mathrm{~T} 3$ \\
\hline $\mathrm{Ca}\left(\mathrm{NO}_{3}\right)_{2} \cdot 4 \mathrm{H}_{2} \mathrm{O}$ & 1 & 5 & 2.5 & 5 \\
\hline $\mathrm{KNO}_{3}$ & 1 & 5 & 2.5 & 5 \\
\hline $\mathrm{MgSO}_{4} .7 \mathrm{H}_{2} \mathrm{O}$ & 1 & 2 & 2 & 2 \\
\hline $\mathrm{KH}_{2} \mathrm{PO}_{4}$ & 1 & 1 & 2 & 2 \\
\hline $\mathrm{CaCL}_{2}$ & 1 & 0 & 2.5 & 5 \\
\hline $\mathrm{KCL}$ & 1 & 0 & 2.5 & 5 \\
\hline$*$ FeEDTA & & 1 & 10 & 10 \\
\hline$* *$ Micronutrientes & & 1 & 1 & 1 \\
\hline $\begin{array}{l}* * * \mathrm{AlCL}_{3} 0,15 \mathrm{M}+ \\
\mathrm{Al} \mathrm{K}\left(\mathrm{SO}_{4}\right)_{2} \cdot 12 \mathrm{H}_{2} \mathrm{O}\end{array}$ & $100 \mathrm{ppm}$ & 0 & 0 & 2.4 \\
\hline
\end{tabular}

* Solução de FeEDTA (Jacobson, 1951):

$26,1 \mathrm{~g}$ EDTA em $286 \mathrm{ml}$ de $\mathrm{NaOH} 1 \mathrm{~N}+24 \mathrm{~g} \mathrm{Fe} \mathrm{SO}_{4}-7 \mathrm{H}_{2} \mathrm{O}$

Arejar por 12 horas. Aferir o volume para 1 litro.

** Solução de microelementos:

$\mathrm{CuSO}_{4} \cdot 5 \mathrm{H}_{2} \mathrm{OH}_{3} \mathrm{BO}_{3} \mathrm{H}_{2} \mathrm{MoO}_{4} \cdot \mathrm{H}_{2} \mathrm{OMnCl}_{2} \cdot 4 \mathrm{H}_{2} \mathrm{O} \mathrm{ZnSO}_{4} \cdot 7 \mathrm{H}_{2} \mathrm{O} \quad 0,08$ g.L.-12,86 g.L $\mathrm{L}^{-1} 0,09$ g.L $\mathrm{L}^{-1} 1,81 \mathrm{~g} \cdot \mathrm{L}^{-1} 0,22 \mathrm{~g} \cdot \mathrm{L}^{-1}$

*** Solução com AlCL $30,15 \mathrm{M}+\mathrm{Al} \mathrm{K}\left(\mathrm{SO}_{4}\right)_{2} \cdot 12 \mathrm{H}_{2} \mathrm{O}$

O material para análise foi coletado aos 15,30, 45 e 60 dias após semeadura, sempre às 14 horas. De cada tratamento foram colhidas folhas saudáveis e totalmente expandidas da parte apical, que se encontravam bem iluminadas. Os vasos para coleta de folhas foram sorteados. Em cada data foram realizadas 3 coletas, para determinação das proteínas solúveis totais e da atividade da glutamina sintetase. 
Para cada um dos três tratamentos, em cada estádio de desenvolvimento, foram retiradas 3 amostras de $0,5 \mathrm{~g}$ de folhas frescas, que foram homogeneizadas em almofariz acomodadas em recipiente com gelo moído. Para cada $0,5 \mathrm{~g}$ de material utilizou-se $1 \mathrm{~mL}$ de tampão de extração (TRIS-HCL 50mM, pH 7,5 acrescentado de $\beta$-mercaptoetanol $2 \mathrm{mM}$ e EDTA $1 \mathrm{mM}$ ) sendo a fase líquida transferida para tubos de centrífuga. $\mathrm{O}$ material foi centrifugado a $10.000 \mathrm{~g}$ por 20 minutos a $0^{\circ} \mathrm{C}$. Após a centrifugação o extrato foi transferido para banho de gelo e imediatamente utilizado para determinação do teor protéico e da atividade enzimática.

O delineamento experimental foi inteiramente casualizado, sendo testado as diferenças na composição da solução nutritiva e diferentes datas de coleta, constituída de 3 tratamentos contendo 3 repetições, sendo cada repetição constituída de 1 vaso de 2 litros contendo areia lavada com 4 plantas.

Os procedimentos estatísticos constaram da aplicação do teste de Tukey para verificar a significância com $5 \%$ de probabilidade, tendo como fatores a composição da solução nutritiva e data de coleta das amostras.

A determinação do teor de proteínas foi realizada pelo método de Bradford (1976), a partir dos extratos obtidos de folhas em tampão de extração. Para tanto se utilizou $0,1 \mathrm{~mL}$ do extrato diluído cinco vezes, acrescentado do reagente de Bradford. A reação produziu coloração que foi lida a $595 \mathrm{~nm}$ em espectrofotometro HITACHI Modelo U-3210. O teor de proteínas foi calculado a partir de uma curva padrão feita com albumina de soro bovino e expresso em $\mathrm{mg}$ de proteína. $\mathrm{g}^{-1}$ de matéria fresca.

A atividade da GS foi medida pelo método de Elliot (1953), o qual explora a atividade biossintética da enzima formando $\gamma$ glutamilhidroxamato. A reação foi conduzida em tubos de ensaio contendo TRIS-HCL 200mM, pH 7,5; 0,2 mL de ATP $50 \mathrm{mM}$, pH 7,0;0,5 mL de glutamato de sódio $500 \mathrm{mM} ; 0,1 \mathrm{~mL}$ de $\mathrm{MgSO}_{4} 1 \mathrm{M}, 0,1 \mathrm{~mL}$ de cisteína $100 \mathrm{mM} ; 0,3 \mathrm{~mL}$ de hidroxilamina $100 \mathrm{mM}, \mathrm{pH} 7,0 ; 0,3 \mathrm{~mL}$ de extrato; totalizando $2 \mathrm{~mL}$ de volume. A reação foi conduzida sob banho Maria $30^{\circ} \mathrm{C}$, sendo interrompida pela adição de $2 \mathrm{~mL}$ de reagente de cloreto 
férrico $-\mathrm{FeCl}_{3}(10 \%) / \mathrm{TCA}(24 \%) / \mathrm{HCL}(6 \mathrm{~N}), 1: 1: 1$ - formando um complexo marrom-amarelado. A leitura colorimétrica foi realizada a 540 $\mathrm{nm}$ em espectrofotômetro HITACHI modelo U-3210. A leitura foi comparada com a curva padrão previamente preparada e expressa em mMols de $\gamma$-glutamilhidroxamato $(\mathrm{GH})$ produzido por hora por miligramas de proteínas.

As determinações da massa de matéria fresca e seca foram feitas após a ultima coleta, as partes aéreas das diferentes repetições foram coletadas e seu peso fresco foi obtido. Essas amostras foram então secas até peso constante em estufa $\left(50^{\circ} \mathrm{C}\right)$.

\section{RESULTADOS E DISCUSSÃO}

As concentrações de proteínas solúveis totais foram analisadas em função das diferenças de solução nutritiva e das diferentes datas de coleta do material. De acordo com a Figura 1, pode-se observar que a concentração de proteínas solúveis totais decresce nos três tratamentos de maneira homogênea para as datas de coleta 15, 30, 45 dias. Na data de coleta de 60 dias, o tratamento constituído da solução de metade da dose de nitrogênio, apresentou um decréscimo acentuado na concentração de proteínas solúveis totais, enquanto os tratamentos com solução completa e solução contendo dose de alumínio mantiveram-se constantes (Tabela 2).

Os resultados da análise da atividade de GS também foram avaliados em função das diferenças de solução nutritiva e das diferentes datas de coleta do material. Como observado na Figura 2, a atividade da GS apresentou um aumento gradativo e homogêneo para todos os tratamentos nas datas de coleta 15 e 30 dias. Para a data de coleta 45 dias observou-se um aumento homogêneo da atividade da GS para os tratamentos de solução completa e solução com metade da concentração de nitrogênio. O tratamento solução completa mais dose de alumínio apresentou um pico da atividade significativa em relação aos outros tratamentos (Tabela 3). Na data de coleta 60 dias, a atividade da GS nos tratamentos de solução completa mais alumínio e solução com metade da concentração de nitrogênio apresentaram uma redução abrupta, as quais 
não diferiram estatisticamente das obtidas no tempo de coleta de 15 dias. Contudo, no tratamento solução completa de Hoagland, verificou-se um aumento da atividade da GS, que coincidiu com o pico de atividade obtido no tratamento solução completa mais dose de alumínio observado aos 45 dias de coleta. Gallo (1980) observou a mesma curva característica para redutase do nitrato.

As variações no peso de matéria seca total são apresentadas na Tabela 4, e os valores obtidos mostram que os tratamentos com solução completa de Hoagland e solução com alumínio não apresentaram diferenças estatísticas do tratamento solução com $1 / 2$ de nitrogênio.

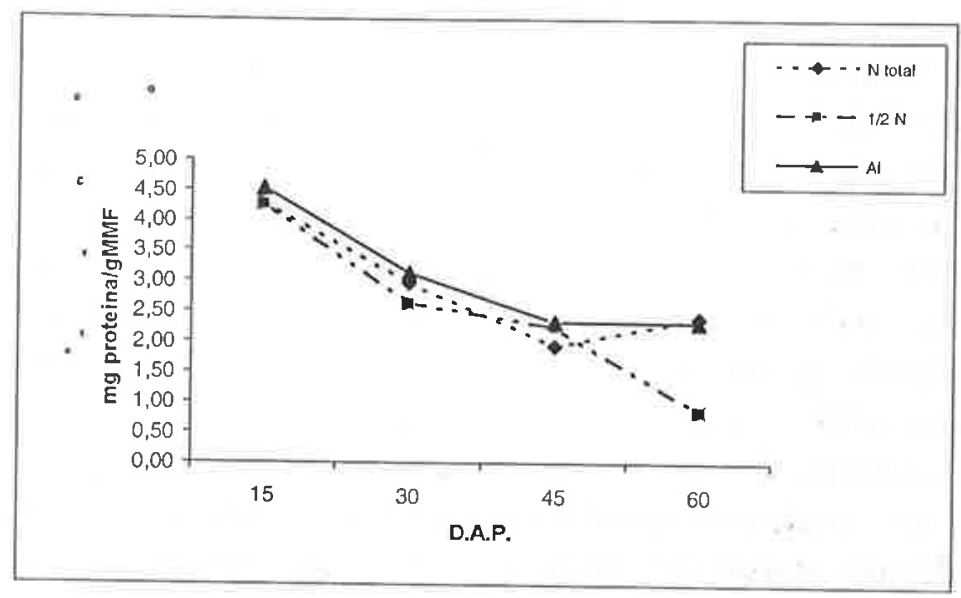

Figura 1: Determinação de proteína solúvel total em plantas de soja (Glicine max L. Merrill cv Br45) cultivadas em casa de vegetação, em três diferentes condições nutricionais: T1: Solução nutritiva de Hoagland \& Arnon 1962 normal, T2: Solução nutritiva com metade da dose original de nitrogênio e T3: tratamento com solução nutritiva normal, mais 100 ppm de alumínio. A proteína foi determinada aos 15, 30, 45 e 60 dias após o plantio (DAP). 


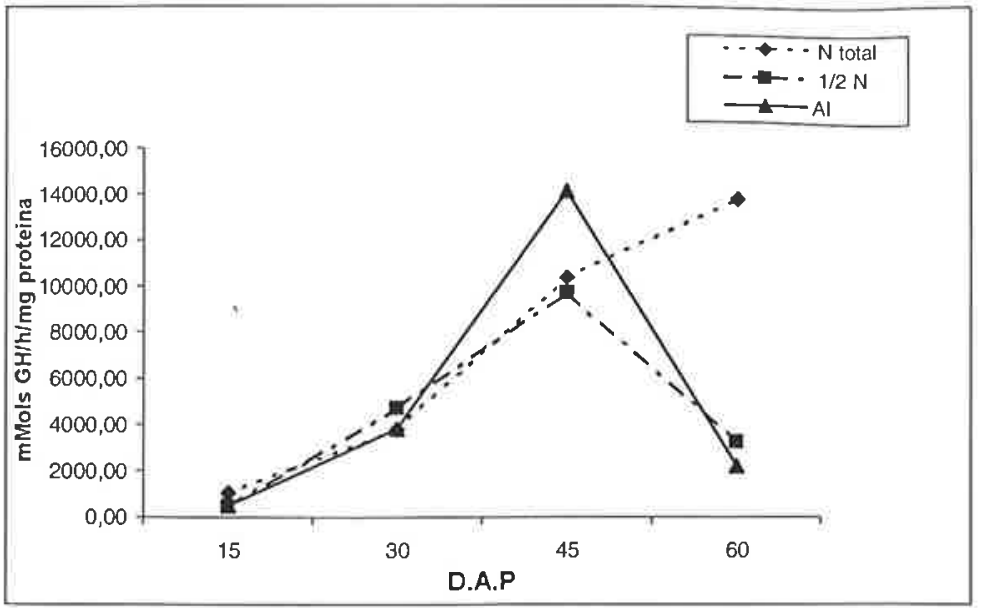

Figura 2: Determinação da atividade da Glutamina Sintetase (GS) em plantas de soja (Glicine max L. Merrill cv Br45) cultivadas em casa de vegetação, em três diferentes condições nutricionais: T1: Solução nutritiva de Hoagland \& Arnon 1962 normal, T2: Solução nutritiva com metade da dose original de nitrogênio e T3: tratamento com solução nutritiva normal, mais 100 ppm de alumínio. A atividade da GS foi determinada aos 15, 30, 45 e 60 dias após o plantio (DAP).

Tabela 2: Médias da interação, composição da solução e data de coleta, sob a variável proteína solúvel total, (mg proteina /g Massa de Matéria Fresca).

\begin{tabular}{|c|c|c|c|c|}
\hline $\begin{array}{rr} & \begin{array}{r}\text { Tempo } \\
\text { (dias) }\end{array} \\
\text { Solução } & \\
\end{array}$ & 15 & 30 & 45 & 60 \\
\hline $\mathrm{N}$ total & $4,2773 \mathrm{Aa}$ & $2,9610 \mathrm{Ba}$ & $1,9270 \mathrm{Ca}$ & $2,2737 \mathrm{Ca}$ \\
\hline $1 / 2 \mathrm{~N}$ & $4,2693 \mathrm{Aa}$ & $2,6153 \mathrm{Ba}$ & $2,248 \mathrm{Ba}$ & $0,9017 \mathrm{Cb}$ \\
\hline $\mathrm{Al}$ & $4,5343 \mathrm{Aa}$ & $3,1247 \mathrm{Ba}$ & $2,332 \mathrm{Ca}$ & $2,3567 \mathrm{Ca}$ \\
\hline
\end{tabular}


Médias seguidas por letras distintas diferem entre si ao nível de $5 \%$ de significância letras maiúsculas representam as diferenças entre linhas, ou seja, em uma dada solução sob diferentes datas de coleta; letras minúsculas representam diferenças entre colunas, ou seja, diferentes soluções na mesma data de coleta.

Tabela 3: Médias da interação, composição da solução e data de coleta, sob a variável atividade da Glutamina Sintetase (GS) (mMols $\mathrm{GH} / \mathrm{h} / \mathrm{mg}$ proteína).

\begin{tabular}{|c|c|c|cc|}
\hline $\begin{array}{c}\text { Tempo dias } \\
\text { Tratamentos }\end{array}$ & 15 & 30 & 45 & 60 \\
\hline $\mathrm{N}$ total & $1051,0233 \mathrm{Da}$ & $4165,5400 \mathrm{Ca}$ & $10399,0300 \mathrm{Bb}$ & $13251,1833 \mathrm{Aa}$ \\
$1 / 2 \mathrm{~N}$ & $474,0167 \mathrm{Ca}$ & $4692,1833 \mathrm{Ba}$ & $9709,4967 \mathrm{Ab}$ & $3116,7600 \mathrm{Bb}$ \\
$\mathrm{Al}$ & $497,3800 \mathrm{Ca}$ & $3817,4167 \mathrm{Ba}$ & $14174,0667 \mathrm{Aa}$ & $2140,0967 \mathrm{BCb}$ \\
\hline
\end{tabular}

Médias seguidas por letras distintas diferem entre si ao nível de $5 \%$ de significância letras maiúsculas representam as diferenças entre linhas, ou seja, em uma dada solução sob diferentes datas de coleta; letras minúsculas representam diferenças entre colunas, ou seja, diferentes soluções na mesma data de coleta.

Tabela 4: Peso de matéria seca total (g) das plantas de soja aos 60 dias. Foram coletas cinco plantas para cada tratamento.

\begin{tabular}{|c|c|}
\hline Trattamentos & Peso de Matéria Seca (g) \\
Solução Completa & $11,06 \mathrm{a}$ \\
\hline Solução com $1 / 2$ Nitrogênio & $8,47 \mathrm{~b}$ \\
\hline Solução com Alumínio & $11.98 \mathrm{a}$ \\
\hline
\end{tabular}




\section{CONCLUSÕES}

O teor de proteinas solúveis totais decresceu ao longo do tempo em todos os tratamentos, sendo que aos 45 dias a concentração de proteina total se estabiliza para os tratamentos com solução completa de Hoagland e solução completa de Hoagland mais dose de alumínio, evidenciando que a dose utilizada de alumínio não altera o teor de proteína solúvel total, entretanto o tratamento com deficiência de nitrogênio não apresentou esta estabilidade aos 45 dias, apresentando uma acentuada queda na concentração de proteína solúvel total, indicando um efeito negativo acentuado da falta de nitrogênio para a concentração de proteína solúvel total. A queda acentuada da proteína solúvel total pode ter ocorrido devido à transferência de proteínas para a formação do grão.

A atividade da GS teve um aumento gradativo e de forma homogênea em todos os tratamentos até o tempo de coleta 30 dias. No tempo de coleta 45 dias, os tratamentos solução completa e solução com metade da dose de nitrogênio mantiveram o padrão de aumento, enquanto o tratamento solução completa mais dose de alumínio apresentou um pico de atividade da enzima e posterior queda aos 60 dias; a solução com metade da concentração de nitrogênio decresceu enquanto a solução completa manteve o padrão de aumento da atividade da GS. Com base nos dados obtidos, é possível identificar uma interferência na atividade da enzima em função da deficiência de nitrogênio ou toxidez por alumínio.

Os dados obtidos com o peso de matéria seca total indicam que as doses de alumínio não foram suficientes para a indução de deficiência nas plantas cultivadas.

\section{REFERENCIAS BIBLIOGRÁFICAS}

BRADFORD, M.M., 1976. A Rapid Sensitive Method for the Quantification of Microgram Quantities of Protein Utilizing the Principle of Protein-Dye Binding. Analyt. Biochem., 72:248-254. BALIGAR, V.C.; FAGERIA, N.K., 1997. Nutrient Use Efficiency in Acid Soils: Nutrient Management and Plant Use Efficiency. In: MONIZ, A.C.; FURLANI, A.M.C.; SCHAFFERT, R.E.; FAGERIA, 
BERGENSEN, F.J. (ed.) Methods for Evaluating Biological

Nitrogen Fixation. New York, John Willey \& Sons, p.265-314. FOY, C.D.; CHANEY, R.L.; WHITE, M.C., 1978. The Physiology of Metal Toxicity in Plants. Ann. Rev. Plant Physiol., 29:511-566. FURLANI, P.R., 1989. Efeitos Fisiológicos do Alumínio em Plantas. IN: SIMPÓSIO AVANÇADO DE SOLOS E NUTRIÇÃO DE PLANTAS, 2, Piracicaba, 1989, Anais. Campinas: Fundação Cargill, p.73-87. GALLO, L.A., 1980. Atividade da Redutase do Nitrato (E.C.1.6.6.2) sob Influência de Fatores Físicos e Químicos em Feijão (Phaseolus vulgaris). Piracicaba, 118p. Dissertação (Mestrado) - Escola Superior de Agricultura "Luiz de Queiroz", Universidade de São Paulo. GAZZARIN, G.G.; SANKHLA, A.; DAVIS, T.D.; SANKLA, D.; SANKHLA, N.; UPADHYAYA, A.; JOSHI, S., 1999. Influence of Growth Regulators on Somatic Embryogenesis, Plantlet Regeneration, and Post-Transplant Survival of Echinochloa frumentacea. Plant Cell Reports, 11:368-371.

HARTWIG E.E., 1973. Varietal Development. In: CALDWELL, B.E.

(ed.) Soybeans: Improvement, Production, and Uses. Madison, WI, ASA Press, p.187-210.

HOAGLAND, D.R.; ARNON, D.I., 1950. The Water Culture Method for Growing Plants without Soil. California Agricultural Experimental Station, 347:1-39.

HOWITT, S.M.; UDVARDI, M.K., 2000. Structure, Function and Regulation of Ammonium Transports in Plants. Biochimica et Biophysica Acta, 1465:152-170.

KASTLER, M., QUEIROZ, E.F.; TERASAWA, F., 1981. Introdução e

Evolução da Soja no Brasil. In: MYASAKA, S \& MEDINA, J.C.

(eds.). A Soja no Brasil. Campinas: Editora ITAL, p.22-24.

LEA, P.J., 1987. Ammonia Assimilation and Aminoacid Biosynthesis.

In: J. COOMBS (Ed.) Techniques in Bioproductivity and Photosynthesis.. Pergamon Press, Chap. 14, p. 173-187.

LEEGOOD, R.C., 1993. The Calvin Cycle and Photorespiration. In: LEA, P.; LEEGOOD, R.C. (Eds.), Plant Biochemistry and Molecular Biology. New York: John Wiley \& Sons, p.27-45. 
